This is the author's final version of the work, as accepted for publication following peer review but without the publisher's layout or pagination. The definitive version is available at http://dx.doi.org/10.1016/j.eiar.2016.12.001

Progressing quality control in environmental impact assessment beyond legislative compliance: an evaluation of the IEMA EIA Quality Mark Certification Scheme

Alan Bond, Thomas B Fischer; Josh Fothergill

Alan Bond (corresponding author) - School of Environmental Sciences, University of East Anglia, United Kingdom; Research Unit for Environmental Sciences and Management, North-West University, South Africa; alan.bond@uea.ac.uk Thomas B Fischer - School of Environmental Sciences, University of Liverpool, United Kingdom; fischer@liverpool.ac.uk

Josh Fothergill - Institute of Environmental Management and Assessment, Lincoln, United Kingdom; j.fothergill@iema.net 


\title{
Progressing quality control in environmental impact assessment beyond legislative compliance: an evaluation of the IEMA EIA Quality Mark Certification Scheme
}

\begin{abstract}
The effectiveness of Environmental Impact Assessment (EIA) systems is contingent on a number of control mechanisms: procedural; judicial; evaluative; public and government agency; professional; and development aid agency. If we assume that procedural and judicial controls are guaranteed in developed EIA systems, then progressing effectiveness towards an acceptable level depends on improving the performance of other control mechanisms over time. These other control mechanisms are either absent, or are typically centrally controlled, requiring public finances; this we argue is an unpopular model in times of greater Government austerity. Here we evaluate a marketbased mechanism for improving the performance of evaluative and professional control mechanisms, the UK Institute of Environmental Management and Assessments' EIA Quality Mark. We do this by defining dimensions of effectiveness for the purposes of our evaluation, and by identifying international examples of the approaches taken to delivering the other control measures to validate the approach taken in the EIA Quality Mark. We then evaluate the EIA Quality Mark, when used in combination with legal procedures and an active judiciary, against the effectiveness dimensions and use time-series analysis of registrant data to examine its ability to progress practice. We conclude that the EIA Quality Mark has merit as a model for a market-based mechanism, and may prove a more financially palatable approach for delivering effective EIA in mature systems in countries that lack centralised agency oversight. It may, therefore, be of particular interest to some Member States of the European Union for ensuring forthcoming certification requirements stemming from recent amendments to the EIA Directive.
\end{abstract}

Key Words: EIA Quality Mark; Effectiveness; Certification; Review

\section{Introduction}

Environmental Impact Assessment (EIA) as a legal tool for decision-making has existed since the enactment of the National Environmental Policy Act (1969) in the United States, and has since spread around the globe to nearly all countries (Morgan, 2012). However, the effectiveness of the process is keenly contested (e.g., Lawrence, 1997; Cashmore et al., 2004; Arts et al., 2012) as 'effectiveness' tends to be a rather plural concept leading some researcher to focus on effectiveness through the eyes of particular stakeholders (e.g., Hayes and Morrison-Saunders, 2007; Hanna et al., 2014). Nevertheless, achieving effectiveness has been argued to rely on a variety of control measures, including legal procedures accompanied by judicial enforcement (Ortolano, 1993; Sanchez, 1993) which, in principle, are guaranteed in mature systems with sufficient capacity, and demonstrated through the existence of case law which helps to define how EIA regulations are understood (see, for example, Macrory, 1994; Weston, 2002; Tromans and Fuller, 2003; Smith, 2007). Other control measures are not guaranteed in the same way, and without appropriate oversight of these other control measures, effective EIA is unlikely to be achieved (Ortolano, 1993). 
That oversight can be facilitated in a number of ways, most of which place additional burdens on the public purse, and so can be resisted by Governments when designing an EIA system. This paper examines an example of a market-based oversight mechanism, the UK Institute of Environmental Management and Assessment's (IEMA) EIA Quality Mark, and evaluates the extent to which it successfully promotes effective EIA.

In order to conduct the evaluation of the EIA Quality Mark, we need to:

1) Define dimensions of EIA effectiveness for the purposes of the evaluation.

2) Identify the control mechanisms that can influence EIA effectiveness, as defined.

3) Investigate global practice in those control mechanisms which are not already guaranteed by legal procedures and an active judiciary (assuming a mature EIA system in a developed country with sufficient capacity to operate their procedures), and determine the extent to which the EIA Quality Mark delivers these additional controls.

4) Introduce the EIA Quality Mark as an example of a market-based mechanism to enhance the effectiveness of EIA.

5) Analyse time-series data of the performance of EIA Quality Mark Registrants to assess the extent to which there is continual improvement.

6) Test the performance of the EIA Quality Mark, against the effectiveness dimensions, as a means of delivering an effective EIA system.

The EIA Quality Mark is a market-based, voluntary certification system and is applied as an additional control mechanism (beyond procedural and judicial) in the United Kingdom which has an EIA system consistent with supranational laws also imposed on the other 27 member states of the European Union $(E U)^{1}$. It is typical of developed countries in having a mature EIA system that largely runs smoothly (Arts et al., 2012), but for which analyses of effectiveness find that "some issues remain unresolved" (Glasson et al., 2012, p.339). The main drivers for IEMA developing the EIA Quality Mark scheme were twofold; firstly, the institute's members were calling for greater centralised action to help catalyse an active community of EIA practitioners to share and improve knowledge. Secondly, IEMA's previous Corporate EIA registration scheme had become outdated, since its launch in the 1990 's, and its members had identified that it required substantive overhaul if they were to continue to seek registration.

The findings presented here should be of potential interest to other EIA systems, for example those that lack equivalent market-based control mechanisms to supplement legal controls, or those that aim at providing them through centralized means (e.g. in the Netherlands through the Commission for Environmental Assessment). The paper builds on Fischer and Fothergill (2014).

Section 2 introduces the forms of control mechanism that have been identified in the literature as having the potential to support effective EIA. Of these, two are of particular relevance in the UK given they are not provided through legislative means: evaluative control and professional control. A typology of effectiveness will also be introduced in this section to act as the basis for evaluation. The associated methodology, which is based on evaluation against an effectiveness framework externally and over time, follows in section 3 and focuses on determining the extent to which the EIA Quality

\footnotetext{
${ }^{1}$ At the time of writing this paper, despite the referendum held on 23 June on the British exit from the EU (BREXIT) the UK was de facto still an EU member state.
} 
Mark, when used in combination with existing legal controls, can deliver an equivalent standard of evaluative and professional control found in more centralized (i.e. non-market based) approaches. Section 4 introduces certification in EIA as a baseline for formal systems to verify the practice of EIA professionals (i.e. exerting professional control) and introduces EIA review as a baseline for formal systems of evaluative control, and the use of environmental licensing (or oversight) authorities; this allows comment on the extent to which the EIA Quality Mark contributes to professional and evaluative control. The EIA Quality Mark is introduced in section 5. In section 6 the performance of the EIA Quality Mark is evaluated against the typology of effectiveness, and includes time-series data that illustrate the extent to which it has acted to improve effectiveness of registrants to the scheme. Conclusions are presented in section 7.

\section{Quality control and effectiveness in EIA}

Ortolano (1993) identified six control mechanisms that influence effective EIA implementation (Table 1).

Table 1 Control mechanisms influencing ElA implementation (adapted from Ortolano, 1993)

\begin{tabular}{|l|l|}
\hline Procedural control & Centralized administrative unit sets EIA requirements \\
\hline Judicial control & Courts investigate and judge allegations of procedural non compliance \\
\hline Evaluative control & $\begin{array}{l}\text { Centralized administrative unit appraises EIA and makes } \\
\text { recommendations to decision makers }\end{array}$ \\
\hline $\begin{array}{l}\text { Development Aid } \\
\text { Agency control }\end{array}$ & $\begin{array}{l}\text { Lending institutions require an EIA before deciding whether to fund a } \\
\text { project }\end{array}$ \\
\hline Professional control & $\begin{array}{l}\text { Project planners have professional standards and codes of practice } \\
\text { leading then to undertake EIA for proposed projects }\end{array}$ \\
\hline $\begin{array}{l}\text { Direct public and } \\
\text { Agency control }\end{array}$ & $\begin{array}{l}\text { Citizens or government agencies apply pressure to influence the EIA } \\
\text { process outside the context of the above controls }\end{array}$ \\
\hline
\end{tabular}

In the United Kingdom as the case study example, procedural and judicial control exist (along the lines set out in Table 1). Case law has continued to develop over the years to refine the 
understanding and practice of EIA (see, for example, Tromans and Fuller, 2003; IEMA, 2011; Glasson et al., 2012), and procedural requirements (as well as some substantive requirements) are established by the relevant Ministry for the sectors listed in the European Union EIA Directive (European Parliament and the Council of the European Union, 2011) as requiring EIA. In the UK, Development Aid Agency control is usually not relevant, neither is direct public and Agency control, albeit some ElAs are conducted on a voluntary basis when not required by legislation (Wood, 2000), and EIA can be influenced through the involvement of the public and statutory consultees (Cashmore et al., 2008).

Thus in this paper we examine the extent to which the approach taken by the EIA Quality Mark to exert evaluative and professional control, in combination with the procedural and judicial control which we assume are provided by the state, acts to deliver an effective EIA process. But there is no agreed consensus on the meaning of ElA effectiveness (Cashmore et al., 2004; Cashmore et al., 2009) and across the years a number of different conceptualisations have appeared. Following on from Table 1, Ortolano (1993) suggested five dimensions:

1. Procedural compliance - did the EIA comply with the rules and regulations?

2. Completeness of EIA documents - are significant impacts covered in adequate detail?

3. Methods to assess impacts - are the methods used for prediction and evaluation appropriate?

4. Influence on project decisions - has the EIA had any influence on decisions, e.g. design modifications, location changes, rejection of application?

5. Weight given to environmental factors - is appropriate weight given to environmental factors?

The fifth dimension is very value-based and falls into the category of normative effectiveness originally proposed by Baker and McLelland (2003). By the very definition this category is problematic given that the weights are likely to change depending on the observer and the decision context and so will not be considered further in this paper where we develop a reproducible understanding of effectiveness for the purposes of our evaluation.

Sadler (1996) highlighted three main categories of effectiveness as part of an international study into effectiveness of EIA: procedural, substantive and transactive. Procedural effectiveness incorporates the procedural compliance dimension proposed by Ortolano (1993)(dimension 1 above), whereas substantive effectiveness, which relates to the extent to which the EIA has achieved its objectives, is reflected in dimensions 2 to 4 , in particular the latter (influence of project decisions). The transactive effectiveness category refers to the efficiency of the process rather than compliance or outcomes (Theophilou et al., 2010); as such it is not considered further in this paper. In addition to these categories, Bond et al. (2013) added consideration of knowledge and learning as being a key goal of impact assessment and therefore a measure of effectiveness (following, e.g., Jha-Thakur et al., 2009). Their reasoning was based on the fact that a good EIA should change the values and actions of stakeholders in relation to their thinking about the environment and therefore have benefits outside the EIA process in the future. They also added a further category of pluralism where they argued an effective process is one where affected and concerned parties are integrated into the 
assessment process, thereby agreeing with Sanchez (1993), who included public control as a key means of delivering effective EIA.

Adding these together, and recognising that many other framings of effectiveness are possible, the following dimensions of effectiveness will be considered as the basis for evaluating the control mechanisms exerted by the EIA Quality Mark in combination with procedural and judicial control:

1. Procedural compliance - did the EIA comply with the rules and regulations?

2. Completeness of EIA documents - are significant impacts covered in adequate detail?

3. Methods to assess impacts - are the methods used for prediction and evaluation appropriate?

4. Influence on project decisions - has the EIA had any influence on decisions, e.g. design modifications, location changes, rejection of application?

5. Development of knowledge and learning - does the approach to EIA develop knowledge and enhance learning amongst stakeholders?

6. Comprehensive involvement - does the approach to EIA engage with members of the public and other stakeholders in a meaningful way at a point in time early enough to influence the conduct of the EIA?

\section{Methodological approach}

Our paper aims at evaluating the EIA Quality Mark when used alongside existing legal control mechanisms against the dimensions of effectiveness developed above. Furthermore, we will look at its ability to lead to improvements over time. As such, time series data recording performance on an annual basis will be used. These rely on the data gathered by IEMA. We acknowledge that they are an imperfect evaluation tool from an objective viewpoint given they rely on the subjective selection of data for comparison by the organisation which benefits (financially) directly from the implementation of the EIA Quality Mark. As such, we particularly aim at contributing to future opportunities for improvement by highlighting gaps in the data in relation to the dimensions of effectiveness.

Following Ortolano (1993), we will focus on a narrative evaluation of the dimensions of effectiveness against the EIA Quality Mark. A level of subjectivity is inevitable in such evaluation, although any conclusions drawn will be justified qualitatively.

\section{Investigating forms of professional and evaluative control}

A brief commentary is provided in this section on the forms of professional and evaluative control that exist in EIA around the world. There are no standards for these forms of control and this commentary does not claim to be comprehensive. Rather it introduces examples of ways of dealing with different forms of control that then act as a basis for validating the approach taken within the EIA Quality Mark. If anything, the lack of systematic evaluations of these forms of control in the literature point to a research gap within the literature on EIA effectiveness. 


\subsection{The role of certification in delivering objective professional control}

The terms 'accreditation' and 'certification' are sometimes used interchangeably, but have different meanings. Certification refers to third party verification of an organization's, or individual's, ability to meet certain standards. Accreditation refers to third party evaluation that an organization's certification programme is run to the appropriate standard. Accreditation schemes are common in the environmental management field, particularly related to environmental management systems where various organisations are accredited to certify the achievement of other organisations of the ISO14001 or EMAS standard, amongst other schemes. Certification systems are also common in environmental management, particularly amongst professional institutes.

For example, the Environment Institute of Australia and New Zealand (http://www.eianz.org/) have environmental professional membership, but this is based on levels of qualification and experience, and so does not certify based on specific skill sets or a set of standards. EcoCanada certify environmental professionals based on a combination of level of experience, educational attainment and specific competencies (http://www.eco.ca/certification/).

Specifically for EIA practitioners, China has had an EIA practitioner licensing system since 1986 (Wang et al., 2003), whereby only license holders can practice. Flanders (in Belgium), also requires compulsory certification of environmental assessment practitioners (and has done this since 1989)(Charlier, 1996). Likewise, the Environmental Assessment Practitioners Association of South Africa (http://eapasa.org/) certifies practitioners, who have to be registered in order to practice, based on certain criteria publicised in their rule book (part of their constitution). They also accredit institutions to deliver training to practitioners, which is then deemed to satisfy some of the criteria.

In the United Kingdom, no such licensing system exists, and IEMA has attempted to fill this gap with a market-based mechanism of certification of practitioners to enhance the quality of EIAs. The scheme works on the basis that the organisations that seek certification (and are successful) can use their 'Quality Mark' as a demonstration of their competence, and may also benefit when third parties seek referrals from IEMA. For the organisations who seek certification, success of the scheme is based on their perception that the value they obtain from being an EIA Quality Mark member exceeds the annual cost of registration. There is no pressure exerted by any government agency to become certified to the EIA Quality Mark.

More recently, the European Union Directive has been amended (European Parliament and the Council of the European Union, 2014) and is due to come into force by $16^{\text {th }}$ May $2017^{2}$; it introduces a new requirement in Article 5, paragraph 3:

"In order to ensure the completeness and quality of the environmental impact assessment report:

(a) the developer shall ensure that the environmental impact assessment report is prepared by competent experts".

Whilst this wording does not demand certification, the need to ensure competence could be met through certification or accreditation schemes and, therefore, it might reasonably be expected that

\footnotetext{
${ }^{2}$ This also applies to the UK, as it will take 2 years to leave the EU, once article 50 of the Lisbon Treaty is triggered (which hadn't happened at the time of writing).
} 
such schemes will develop in some EU member states, where they do not already exist, either as voluntary or compulsory requirements. As such, IEMA's EIA Quality Mark may be of considerable interest where governments are keen not to take on additional administrative (and therefore cost) burdens.

IEMA's EIA Quality Mark counts as a certification scheme in that organisations are evaluated against a set of criteria and the Quality Mark is only awarded to those deemed to have met the standard required. Across the literature, there is no agreement on what these standards should cover, or at what level they should be set.

\subsection{Approaches for delivering evaluative control}

To an extent, evaluation was built into NEPA (1969) via the requirement for the lead agency to respond to other agency, and public, comments on a draft Environmental Impact Statement (EIS) (Canter, 1996; Wood, 2003). Thus the evaluation is procedurally controlled, but is not systematic, given it depends on who takes the time to respond and the particular approach taken.

A methodological approach to assist with the evaluation of Environmental Impact Statements (EIS; the main documentary product of the EIA process) was provided via the development of quality review packages. These initially developed in 1990 based on one used in a Master's project undertaken at the University of Manchester in 1989 (Lee and Brown, 1992; Lee and Colley, 1992). This review package was designed to be used to assess the quality of environmental impact statements prepared for projects falling within the remit of land use planning in the United Kingdom. The review works by setting out criteria which are used to categorise environmental impact statement quality into four review areas, each with additional categories, with each category having further sub-categories. Readers are directed to Lee et al. (1999) for a full explanation of the development and functioning of the review package. Variations of the package were subsequently used on numerous occasions by a number of authors (e.g., Barker and Wood, 1999; Phylip-Jones and Fischer, 2013). These have usually found a slow and small increase in the quality of EISs over time. Other review packages have been developed and used, usually applied to particular circumstances. For example, the Impacts Assessment Unit at Oxford Brookes University developed a review package to investigate the changing quality of environmental impact statements on behalf of UK Government and applied it to EISs of planning projects in the UK in 1995/96 (Glasson et al., 1996; Glasson et al., 2012). The European Commission also developed a series of guidance documents designed to help member states of the European Union implement the Directive on Environmental Impact Assessment (Council of the European Communities, 1985); one of these was specifically on review (Environmental Resources Management, 2001a). Variations of the above review packages have been developed for other impact assessment areas, for example health impact assessment (Fredsgaard et al., 2009) and strategic environmental assessment (Fischer, 2010), and they have also been modified to focus on specific impact components, e.g. for the aquatic environment (Badr et al., 2004), for ecological impacts (Thompson et al., 1997; Byron et al., 2000), for cultural heritage (Bond et al., 2004), and an avian and bat assessment quality index has also been derived (Chang et al., 2013). However, these review packages are simple methods which, in the context of evaluation of EIA, have two particular shortcomings: 1) they are rarely formally required; and 2) they evaluate only the written document and not the EIA process. 
Ortolano (1993) gave the example of the Fundação Estadual de Engenharia do Meio Ambiente (FEEMA) in Rio de Janeiro, Brazil as providing a formal mechanism for evaluation (now renamed Instituto Estadual do Meio Ambiente (INEA)). In Brazil, the EIA regulations are set at a Federal level by the National Council of the Environment (CONAMA) (Glasson and Salvador, 2000). At the Federal level, the Brazilian Institute of Environment and Renewable Resources (IBAMA) are the environmental licensing authority (Glasson and Salvador, 2000) which, for some projects, organise a multidisciplinary team to prepare the scope of the EIA; they subsequently receive the EIS and it is evaluated by the same team, who can seek additional information. IBAMA then have the authority to issue (or withhold) the environmental license. Some, not all, of the states have their equivalent agencies (to IBAMA) (Sánchez, 2013), including INEA in Rio de Janeiro. Other jurisdictions have adopted similar approaches, for example, Western Australia, where the Environmental Protection Authority (EPA) advises the Minister for the Environment subsequent to public review, with the system also allowing for public appeal of the EPA advice (Morrison-Saunders and Bailey, 2009); in Portugal a Regional Environment Director has the authority to approve or reject an EIA Report (Pinho et al., 2007). A similar process has operated in the Netherlands since the late 1980s where the Netherlands Commission on Environmental Assessment performs the same tasks, on the same formal basis, with the key difference being that the Commission has no formal decision making powers and can only make recommendations to the competent authority (Wood, 2003). These examples share in common the fact that the evaluating organisation is funded with public money.

The European Commission delivers evaluative control through periodic five-year reviews of the EIA Directive. These gather information from member states on their implementation of the Directive, and help to highlight weaknesses and areas where harmonisation might lead to more consistent application (thereby reducing any economic anomalies through distortion of competition by introducing different - e.g. environmental - standards where it becomes cheaper to develop in one member state than another). The five year reviews lead to periodic amendments to the Directive, a particularly significant one leading to wholesale changes of the screening requirements in 1997 (Commission of the European Communities, 1997; Council of the European Union, 1997).

Based on the practice outlined above, the EIA Quality Mark undertakes a rigorous review of the Environmental Impact Statements, and it undertakes periodic reviews (annually) in order to ensure continued compliance. As a voluntary scheme, it has no involvement in the EIA itself - instead it feeds back to the applicants to the scheme outside the formal process. As such, it has no influence on any individual EIA. Rather, the aim is to ensure the competence of the consultants on an ongoing basis.

\section{Introduction to the IEMA EIA Quality Mark - progressing quality?}

IEMA is the professional home of over 15,000 environment and sustainability professionals from around the globe. A substantial proportion of its membership work in fields related to environmental management and assessment in the United Kingdom. Although there are a number of other associations which include EIA within their remit (e.g. Chartered Institute of Ecology and Environmental Management - CIEEM, Royal Institution of Chartered Surveyors - RICS, Chartered Institute of Water and Environmental Management - CIWEM), IEMA is by far the largest professional body for those specialising in EIA and SEA, not just in the United Kingdom, but also worldwide. 
The IEMA EIA Quality Mark began operation in April 2011 and can be sought by those organisations which produce some of the approximately 800 Environmental Impact Statements (EISs) currently submitted each year in the United Kingdom. The aim of the EIA Quality Mark is the continuous improvement of EIA quality (not just improvement of EIS documents) with a specific aim to reduce or eliminate poor quality EIAs. A critical component of the aim is that the EIA Quality Mark defines acceptable quality as being better than the statutory minimum requirements, which do not incorporate all elements of effectiveness as outlined above. The EIA Quality Mark thus aims to ensure that the lowest level of quality achieved across all EISs is higher than legislative compliance.

There were 38 organizations registered as founding members of the EIA Quality Mark at its launch on $18^{\text {th }}$ April 2011, which included organisations that completed the transition from IEMA's previous corporate EIA register and those who piloted the scheme's application process during 2010. Four years later, in the summer of 2016, there were 56. Whilst indicating net growth over time, the total number of registrants will occasionally fall due to mergers / acquisitions in the ElA consultancy market and the need to remove registrants who fail to comply with the scheme's requirements. The registered organisations represent $92 \%$ of the UK's top 25 environmental consultancies, by revenue (Environment Analyst, 2015), and combined the companies account for at least one-third of all EIAs conducted every year in the United Kingdom. The application fee is between $£ 2,200$ and $£ 2,750$, depending on whether the environmental consultancy is a 'small producer' ( $\leq 3$ EISs per year) or a 'large producer' ( $\geq 4$ EISs per year). The annual fees for seeking continued registration are then between $£ 1,100$ and $£ 1,650$ for small and large producers respectively.

\subsection{The seven commitments of the EIA Quality Mark}

The EIA quality mark is built on seven commitments (referred to as COMs). These are formally signed up to by a senior figure responsible for each registrant's EIA practice. The commitments focus on EIA-management; team capabilities; legal compliance; EIA context and influence; EIA content; EIA presentation; and improvement of EIA practice. This is explained in more detail below. The seven commitments are evaluated by an EIA Quality Mark Panel, members of which are independent EIA experts, who do not work for an organisation registered to the scheme, or an organisation that could register to the scheme; as such, the majority are drawn from micro-consultancy organisations (those with $<5$ staff) or from academic institutions. All panel members must meet specific knowledge and skills requirements set out by IEMA and undergo training and a period of review before formally joining the panel.

The scoring system for all COMs has been modified extensively from that used by the Lee et al. (1999) review package; there are just three grades used: 'pass', 'fail' or 'concerns'. Each grading needs to be accompanied by text to justify its award. Pass means the quality is as expected, fail means that the standard is too low, and for concerns the reviewer identified inadequacies, omissions or issues that mean a Pass grade cannot be given. As for Lee et al. (1999) each commitment is given an overall grade based on a judgement of the reviewer, based on the response to the individual questions and the grades awarded at that more detailed level.

1 ElA management

Compliance with this obligation is determined by a telephone interview, conducted on application to join the scheme and then reassessed at least every three years, with a senior manager responsible 
for the organisation's EIA work. The questions relate to the EIA-procedure (effective management and quality control as well as an understanding of the influence of the EIA carried out on projects, that is - the outcomes), the management of quality in the company and amongst its individuals, the effective management of subcontractors and suppliers, effective and consistent communication with clients and other stakeholders, as well as the presence of management systems (mostly based on ISO - International Organization for Standardization - standards).

\section{EIA-team capabilities}

Compliance with this obligation is partly assessed using the same senior manager interview. In addition, two to four Interviews (depending on the number of EISs produced by the organisation in the previous year) are carried out on an annual basis with other (more junior) staff. The questions include the hiring process for new employees as well as their induction and access to mentoring. The focus is on determining how project teams are formed and how EIA knowledge and learning are maintained and renewed. The questioning also includes access of the interviewees to professional training opportunities and membership of professional organizations.

3, 4, 5, 6 EIA regulatory compliance, taking account of the context, as well as the content of EIAs and Presentation

Compliance with obligations 3 to 6 takes an audit based approach, using a detailed review of one or, if the initial review highlights concerns, two EISs, selected at random, from those completed by the registrant over the past two years. The test criteria are based on compliance with statutory provisions, the impact of EIA on project planning, contents of the created EIS as well as the presentation and readability of the EIS. The EIA Quality Mark does not use two reviewers as recommended by (Lee et al., 1999), instead a single reviewer is used who follows criteria guidance and attends regular standardisation meetings across the review panel to ensure consistent interpretation. Each review is also moderated within IEMA to ensure consistency of evaluations and adequacy of justification of gradings. This is a pragmatic means of ensuring accurate reviews without placing excessive cost burdens on the organisation seeking accreditation (as the fees charged need to cover the cost of Panel members' time). Any concerns or fails at the commitment level for any of COMS 3-6 lead to a requirement to check a second EIS. If the concerns or fails remain, then IEMA determines whether an improvement plan would be required, or whether to remove the registrant from the scheme.

In general this task (COMs 3-6) is a criteria-based review of EISs similar to the operation of existing review packages. IEMA previously provided a form of accreditation to environmental consultants based on their own review package which was a modified version of Lee et al. (1999).

\section{$7 \quad$ Improvement of EIA practice}

Commitment 7 requires that all EIA Quality Mark organisations contribute to improving EIA practice each year. All registrants are required to submit all their completed EISs to IEMA on an annual basis. IEMA then maintains a database of full EISs in their offices which at the time of writing holds over 1600 UK EISs (and related addenda) prepared between 2009 and 2016. There is also a minimum level requirement for each organisation to prepare short articles on elements of good practice (approximately 750 words) for the IEMA magazine 'The environmentalist' as a means of 
disseminating such practice to the wider EIA community. In addition, one or two lectures on EIA, either through a workshop, a conference or one of the regular IEMA webinars must be given by each EIA Quality Mark organisation. Finally, each year each registrant must prepare a 2-page EIA-case study which is stored in a dedicated IEMA library (with over 230 submitted to date). However, as the scheme has evolved, these minimum requirements can be exchanged for taking a more proactive and in-depth role in the development of a specific piece of guidance, with guides on ecosystem services, non-technical summaries, climate change resilience and EIA's role in both, shaping and delivering quality development produced between 2012 and 2016.

Table 3 sets out the key categories of the commitments of the EIA Quality Mark. Each of the subcriteria, set out in the form of questions, helps assessors to award a grade.

Table 3 Key EIA Quality Mark criteria (Source:

http://www.iema.net/assets/uploads/applicant_guide_eia_quality_mark_march_2014.pdf

COM 1 EIA Management

A. Ensuring consistent EIA Quality across the organisation

B. Ensuring consistent EIS Quality across the organisation

C. Providing consistent direction on the approach to communicating with EIA stakeholders

D. Understanding the influence of the organisation's EIA services

COM 2 EIA Team Capabilities

A. Progressing EIA staff development through mentoring

B. Supporting EIA staff in maintaining appropriate professional membership

C. Maintaining and updating EIA knowledge across the organisation

COM 3 EIA Regulatory Compliance

A. Description of the development

B. Outline of the main alternatives studied by the developer

C. Data required to identify and assess the main effects on the environment

D. Assessment of environmental effects

E. Interaction between the factors set out under COM3 D.

F. Significant effects on the environment

G. Mitigation measures

H. Non-Technical Summary

I. Difficulties encountered in compiling the information presented in the ES

COM 4 EIA Context \& Influence
A. Scoping
B. Alternatives, including iterative design
C. Consultation 
COM 5 EIA Content

A. Baseline

B. Assessment

C. Environmental Mitigation and Management

COM 6 EIA Presentation

A. ES Quality

B. Non-technical summary

Thus each registrant obtains feedback on their performance in relation to some of the COMs annually. All COMs (1-6) are tested at initial registration. COM1 is then tested every three years, COM2 annually and COMs 3-6 are tested, using an approach where COMs $3 \& 4$ are tested one year followed by COMs $5 \& 6$ the next year - and this continues to alternate on this basis annually. The difference in fees for initial, and ongoing registration explain the reasoning for this pragmatic approach which aims to maintain affordability whilst continually evaluating quality.

\subsection{EIA Quality Mark in practice - improving quality?}

The dimensions of effectiveness set out in section 2 are mapped against the specific EIA Quality Mark commitments in Table 4. Subsequently, a brief analysis is presented of the performance of EIA Quality Mark registrants against these dimensions to illustrate the extent to which quality is enhanced (if at all).

Table 4 Mapping of the dimensions of effectiveness against EIA Quality Mark commitments

\begin{tabular}{|l|c|}
\hline Dimensions of effectiveness & $\begin{array}{c}\text { Covered by the EIA Quality } \\
\text { Mark in: }\end{array}$ \\
\hline Procedural compliance & COM 3 (A-I) \\
\hline $\begin{array}{l}\text { Completeness of EIA } \\
\text { documents }\end{array}$ & COM 4 (A) \\
\hline Methods to assess impacts & COM 5 (B) 1 (Aiii) \\
\hline $\begin{array}{l}\text { Influence on project decisions } \\
\text { COM 4 (Biii) }\end{array}$ & COM 2 (A, B, C and D) \\
\hline $\begin{array}{l}\text { Development of knowledge } \\
\text { and learning }\end{array}$ & COM 7 \\
\hline
\end{tabular}




\begin{tabular}{|l|c|}
\hline Comprehensive involvement & $\begin{array}{c}\text { COM 1 (Di \& ii) } \\
\operatorname{COM~4~(C)~}\end{array}$ \\
\hline
\end{tabular}

\section{Discussion}

In this section, the EIA Quality Mark will be evaluated against the six evaluation dimensions as introduced in section 2: Procedural compliance; Completeness of EIA documents; Methods to assess impacts; Influence on project decisions; Development of knowledge and learning; Comprehensive involvement.

\subsection{Procedural compliance}

The EIA Quality Mark analyses EISs against a set of criteria which determine whether the contents deliver all that is required in the legislation. This satisfies this dimension in the same way that formal reviews conducted by, for example, IBAMA (Sánchez, 2013), or the Dutch EIA Commission (Wood, 2003) check to ensure the contents are as previously specified. Procedural compliance in the UK is to an extent delivered through legislation and access to the Courts in any case; however, the EIA Quality Mark does provide a systematic evaluation, rather than relying on third parties to seek redress through the Courts for non-compliance. There is some suggestion that compliance has improved, on average, since the advent of the Quality Mark (Figure 1), although there is variation and the improvement is not clear cut enough to conclude causality.

There are no directly comparable results to the EIA Quality Mark, but previous reviews of EISs using the Lee \& Colley review package (Lee and Colley, 1992) in the UK have revealed a much lower proportion have been satisfactory, but that this proportion has increased over time (for example from 58\% in a sample between 1990-1991 to 66\% between 1994 to 1996 in the UK; with the overall improvement in equivalent samples across eight EU countries progressing from 50 to $71 \%$ across the same time period (Barker and Wood, 1999)). Figure 1 suggests that procedural compliance continues to improve, although caution must be exercised given the sample is restricted to those consultancies who choose to implement the EIA Quality Mark, and a different scoring scale is used to that developed in the Lee and Colley (1992) review package. 


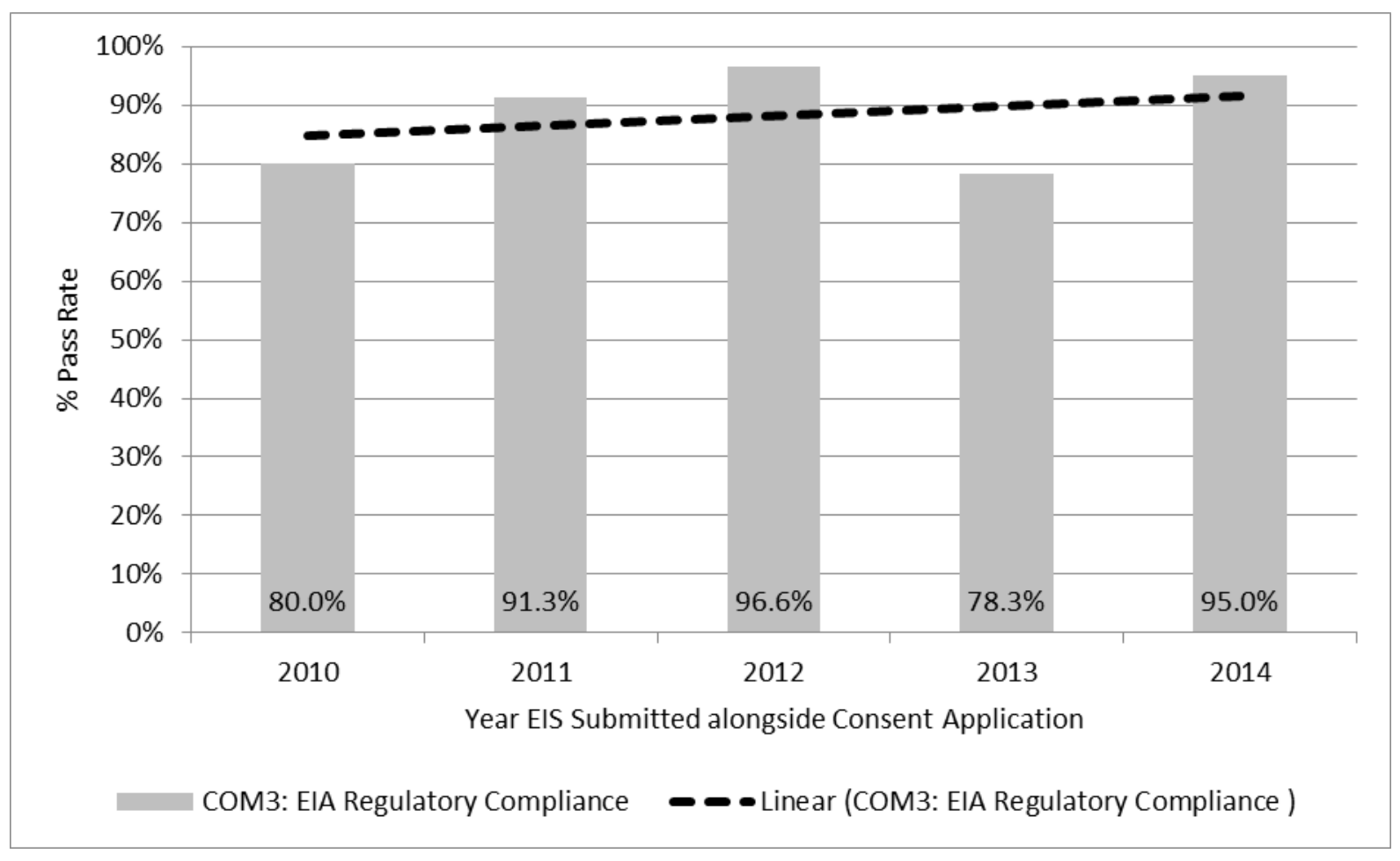

Figure 1 Procedural compliance of EIA Quality Mark registrants and applicants EISs

\subsection{Completeness of EIA documents}

As for 6.1, the EIA Quality Mark analyses the EIS based on evaluation criteria. A particular focus is the scoping (COM4A) that has been undertaken and the extent to which that has been comprehensive. Any failings might lead to re-analysis of another EIS produced by the same consultancy company and a repeated failure can lead to refusal of the Quality Mark. In the short term this has no influence on the EIS which has already been submitted and used as part of the decision process. The failure to achieve the EIA Quality Mark is assumed to lead to improved practice in order to achieve registration in future. Figure 2 suggests a modest trend towards improvement in completeness over time, although the evidence is not compelling at this stage.

Weston (2000) argued that political factors are important in scoping in the UK which precludes a rational process. Scoping has been the subject of guidance from the European Commission (Environmental Resources Management, 2001b) and also from a statutory consultee in England and Wales (Bond and Stewart, 2002), recognising its importance. The Department for Communities and Local Government commissioned an evidence review of scoping, predominantly in England \& Wales (EIA Centre University of Manchester et al., 2006) to investigate practice; in the UK the request of a scoping opinion is discretionary under regulations and in 2006 62\% of opinions were based on scoping reports provided by the EIA consultants. IEMA published a review of practice in 2011 for the UK (IEMA, 2011) which suggested that scoping reports had become too long (as they can be over 100 pages) which was starting to place unnecessary burdens on competent authorities when asked for an opinion. The EIA Quality Mark assesses performance of the 'scoping process' outlined in the EIS in terms of the strength of justification made, and the extent to which the issues scoped in are fully assessed. As such, the more recent concerns about the potential for scoping to become 
burdensome are missing. Nevertheless, Figure 2 suggests that scoping is improving in terms of the completeness of the EISs evaluated.

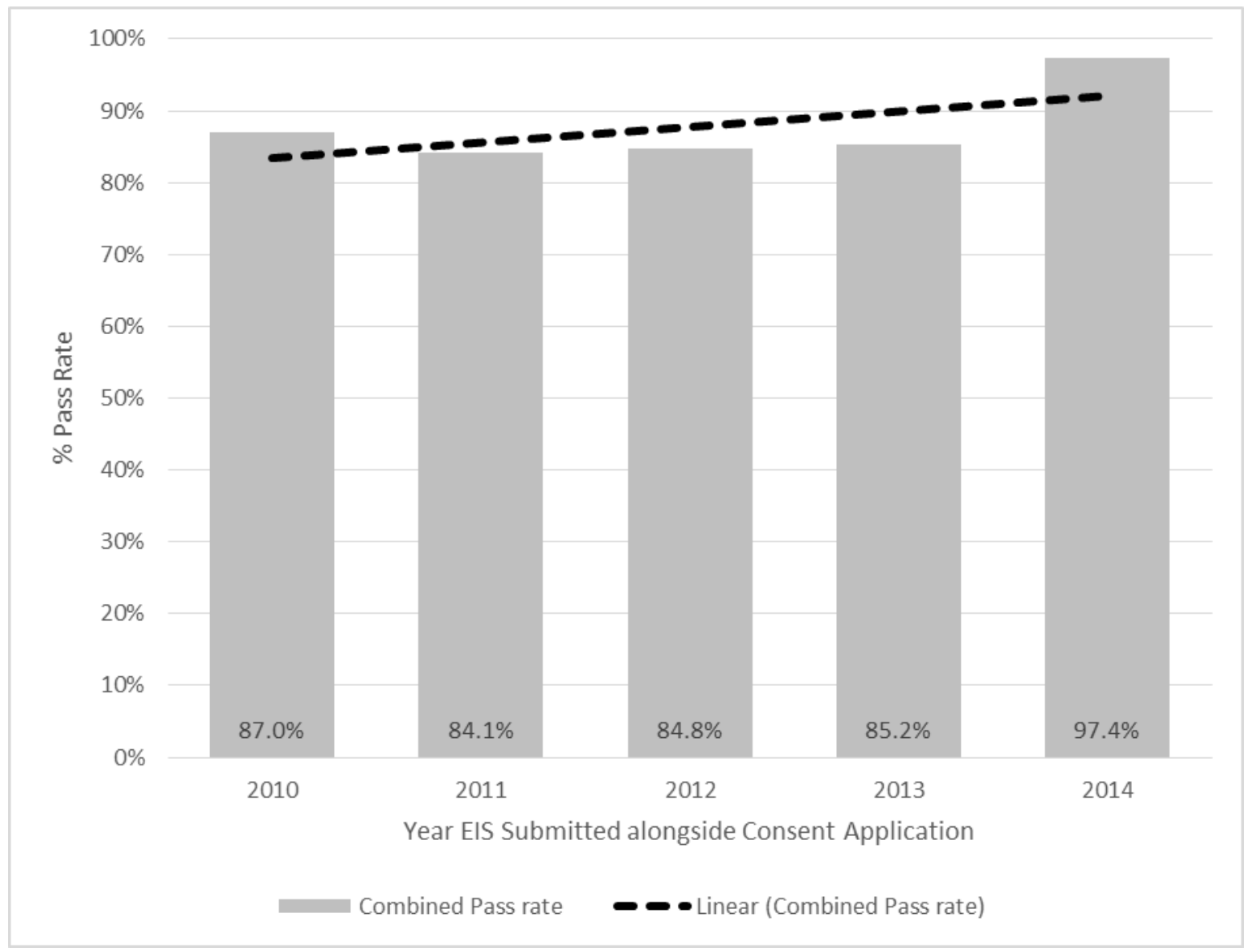

\section{Figure 2 EIS Completeness of EIA Quality Mark registrants and applicants' EISs}

The EIA Quality Mark does examine the extent to which suitably experienced consultants are employed on particular projects (through semi-structured interview questions in COM1), and also examines the controls they have in place for ensuring the competence of sub-contractors employed to write specialised chapters of an EIS that they cannot cover in house. Registrants are expected to be ISO9000 and ISO14001 certified, and to have robust sign-off procedures in place. Thus it does go further than legal compliance which would simply require that certain process steps had been undertaken.

\subsection{Methods to assess impacts}

The EIA Quality Mark makes no attempt to assess the suitability of specific impact prediction and evaluation techniques, though it does ask whether methods used in this context are justified. The evaluation therefore relies on the technical judgement of EIA Quality Mark panel members, although they can determine the consistency of application of methods across impact types. The expectation for non-market control mechanisms is different given that they are typified by the allocation of multi-disciplinary teams to work on particular EIAs. As such, the IEMA Quality Mark shares a weakness common to some other review-based methods that the review is designed to be conducted by non-specialists (Lee et al., 1999) who therefore have limited ability to comment on the adequacy of the more technical content. 
COM5B examines the adequacy of methods for determining magnitude, consistency of approach for determining significance throughout the EIS, coverage of stages of development (construction, operation, decommissioning), inclusion of positive as well as negative effects, inclusion of interactions and cumulative effects and documentation of residual effects (Figure 3). Determining significance is recognised as the most critical element of EIA (Wood et al., 2007; Ehrlich and Ross, 2015), yet Lawrence (2007, p.731) argues that "little or no effort tends to be made to describe the detailed attributes of the approach or to recognize and respond to the strengths and limitations of the proposed approach". Most significance determination contains elements of technical and more judgemental elements (Ehrlich and Ross, 2015) and the EIA Quality Mark focuses on the transparency and appropriateness of these elements, without expecting consistency across all environmental aspects considered in an EIA (IEMA, 2011).

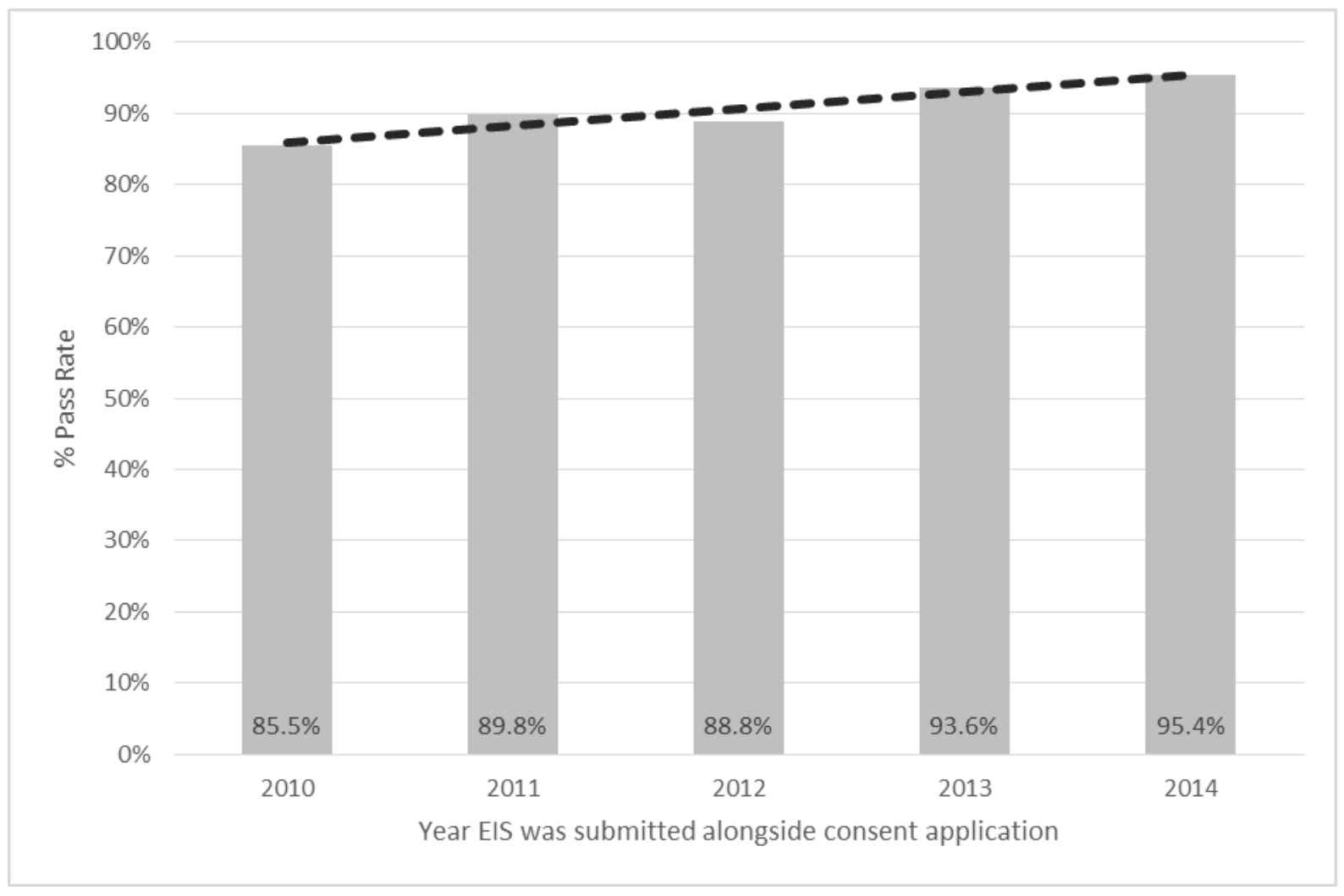

Figure 3 Aggregate pass rate for elements of methods of EIA Quality Mark registrants and applicants EISs

\subsection{Influence on project decisions}

Legislation dictates that EIAs have to inform decision making and, through enforcement via the courts, can influence decisions and possible rejection of applications. Non-market mechanisms, e.g. the role of IBAMA in the Brazilian federal system, lead to specific decisions on environmental licenses (Sánchez, 2013). Yet there remains considerable doubt over the influence that policy tools like EIA exert over decision-making (Cashmore and Axelsson, 2013). It is clearly beyond the remit of the EIA Quality Mark to specifically answer this question as it engages with the EIS and the consultants only. Nevertheless, the review of the EIS asks the specific question: "Does the ES clearly indicate how the EIA process, environmental effects and consultee responses influenced the iterative design process that led to the proposed development?" (COM4B-iii). So it is instrumental in 
determining the registration to the EIA Quality Mark and seeks to ensure future good practice on behalf of the consultant (see Figure 4 for performance of EIA Quality Mark registrants which does not suggest an improvement over time). The IEMA Quality Mark also includes interview questions that ask about the influence of their EIA services in terms of the value added to the client, and also whether auditing of impacts takes place (COM1A-iii)(see Figure 5). This is an attempt to investigate influence in other ways.

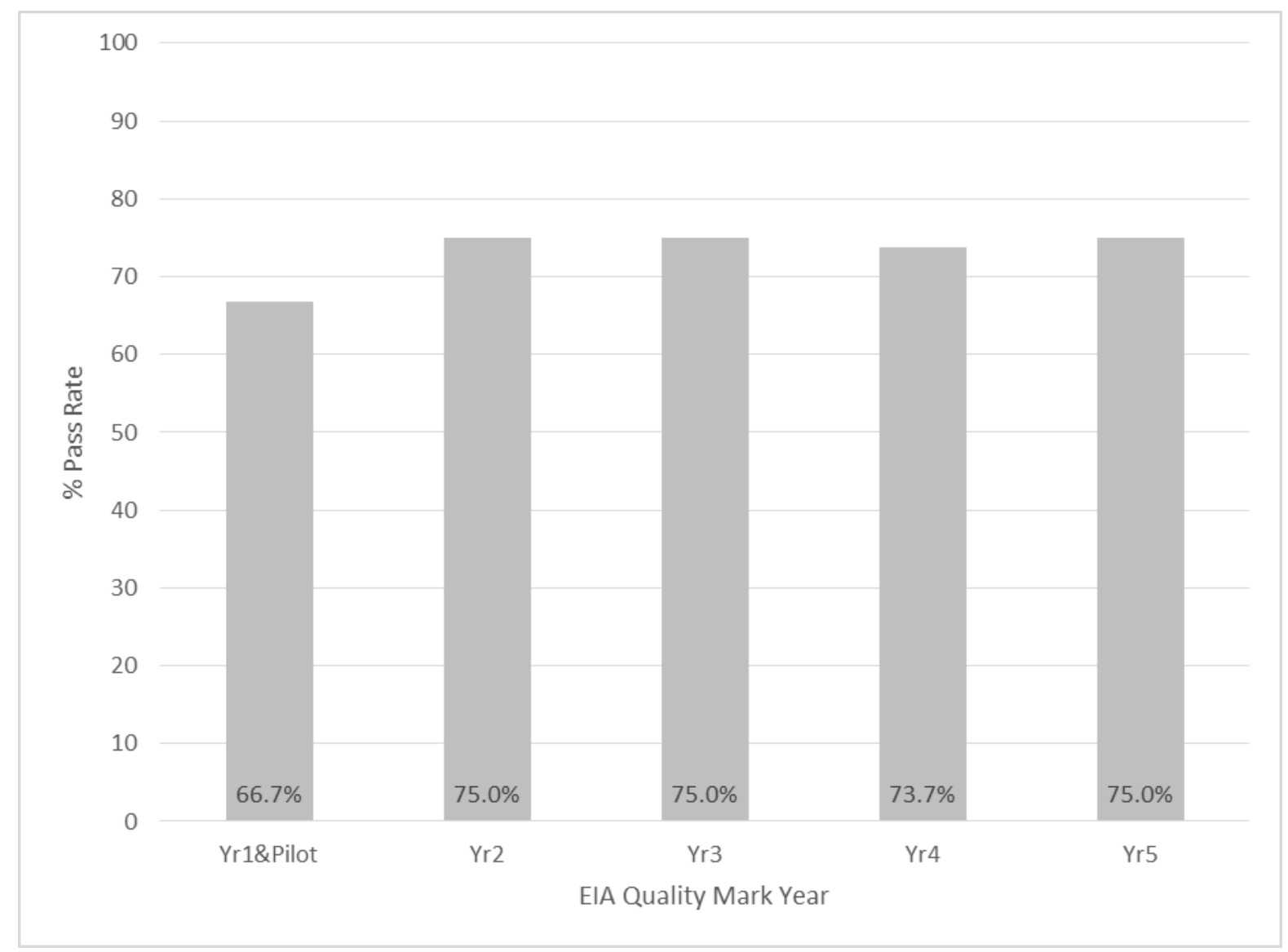

Figure 4 Understanding the influence of the EIA Quality Mark registrant's EIA services 


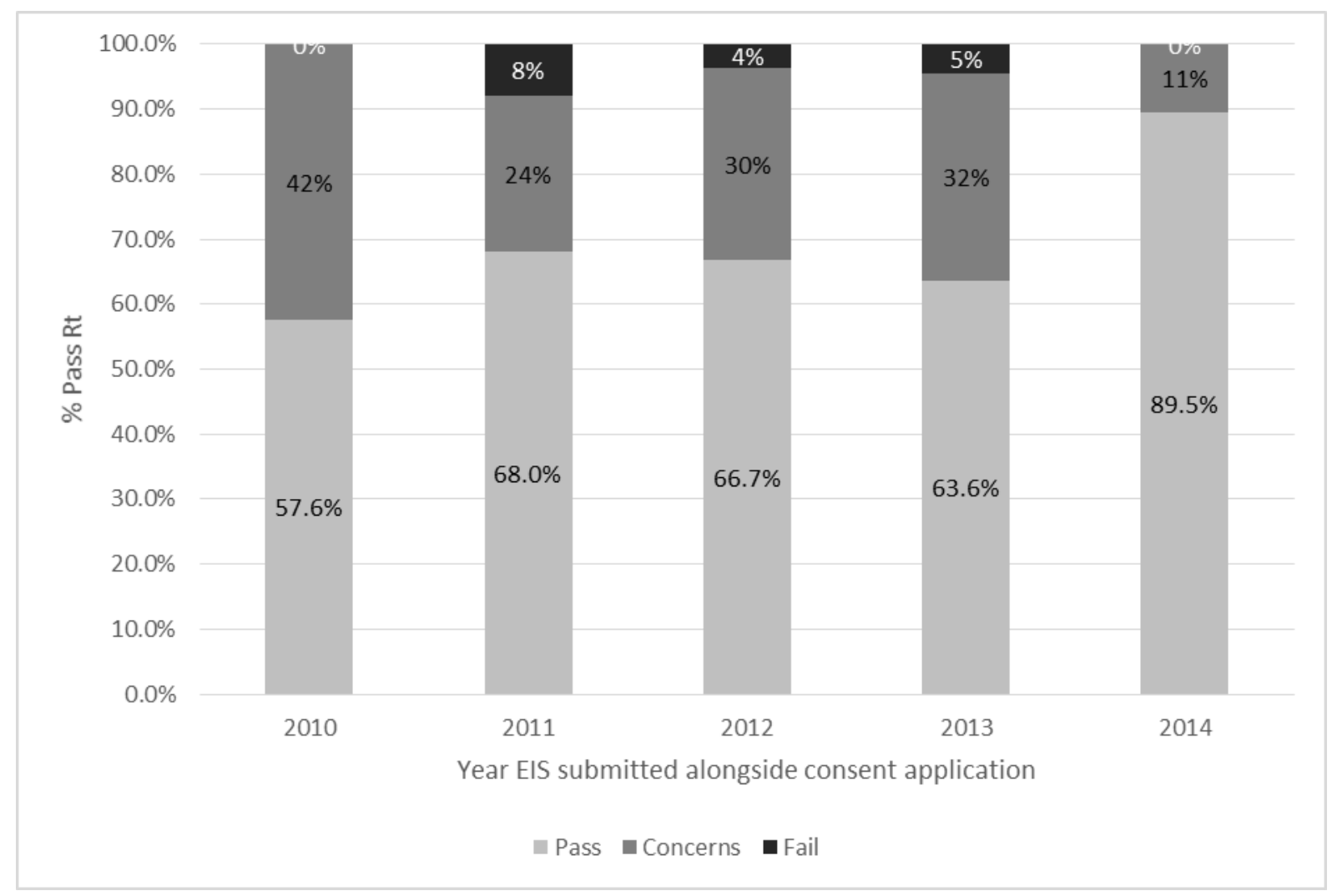

Figure 5 Understanding the influence on the iterative design process of the EIA Quality Mark registrant's EIA services

\subsection{Development of knowledge and learning}

For learning, the distinction between different types of learning are useful: instrumental learning (also called single-loop learning) is that which leads to changes in project design (Sinclair and Diduck, 2001); double-loop learning leads to changes in beliefs and therefore is expected to be retained and applied to future projects - leading to better design from the start; De Jong et al. (2012) refer to this as internalisation and argue that it takes much longer than single loop learning. Runhaar et al. (2010, p.340) highlight one element of double loop learning to be "A feedback loop concerning personal or organisational values and goals; reflection upon the question whether the right things are being done". For non-market control mechanisms, the pathway for enhancing knowledge and learning is indirect as incentives are put in place for learning that leads to better performance. Based on JhaThakur et al. (2009), requests for changes to the EIA made by the decision-maker to the proponent may lead to double-loop learning (forcing organisational reflection), but in practice this is very rarely observed (Fischer et al., 2009).

The EIA Quality Mark does specifically assess mechanisms for ensuring up-to-date knowledge throughout those working on EIA within a registrant, and also examines the extent to which consultancies embed and finance learning within their employees. For example, COM2A evaluates staff recruitment, induction \& mentoring and the extent to which it supports ongoing quality and learning; COM2B evaluates the delivery of quality through effective EIA team selection processes; $\mathrm{COM} 2 \mathrm{C}$ evaluates internal EIA communication and feedback specifically in terms of maintaining and 
updating EIA knowledge across the organisation and ensuring the organisation takes up and implements developments in EIA; and COM2D evaluates performance management and EIA team development, with an expectation that members will financially compensate staff for professional membership, and will support ongoing continuous professional development (see Figure 6). COM7 is also designed to share learning between member organisations and there is evidence of widespread uptake of these opportunities. Together these evaluations identify evidence for single-loop learning.

Organisational reflection, leading to double loop learning, is not tested through the EIA Quality Mark. However, COM1, which looks at EIA Management, might lead to reflection by organisations when considering the extent to which they add client value, ensure consistent quality, and effectively manage the EIA process. Any concerns highlighted by the review would be expected to lead to reflection and an improvement plan, irrespective of a consultancy potentially reflecting on the feedback they obtain when they pass all COM1 criteria. There are examples of regsitrants failing one year, submitting an improvement plan, and then passing in the failed area in the subsequent year. However, causality for the improvement is not examined and it remains the case that the EIA Quality Mark cannot identify where double-loop learning has occurred.

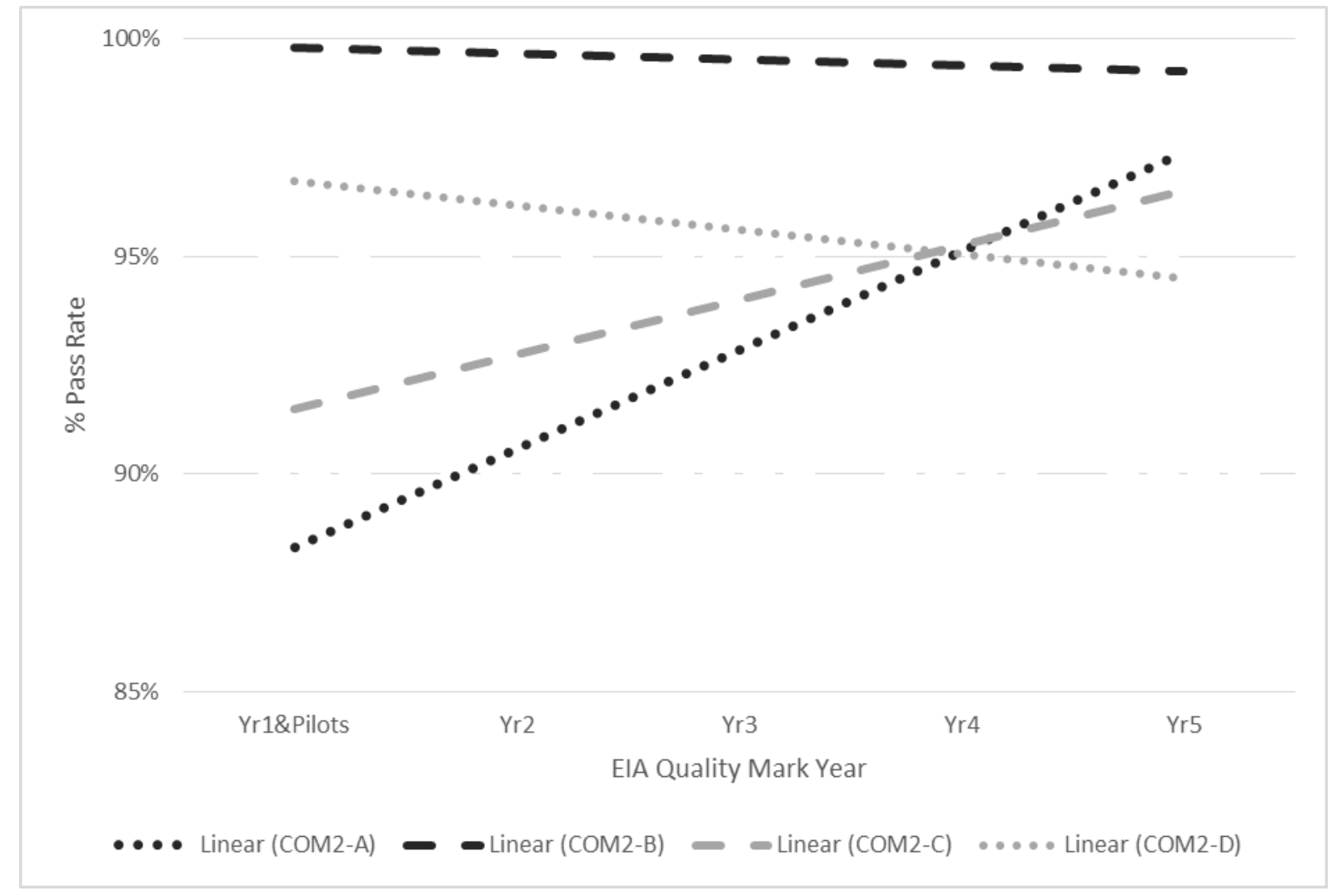

COM2A: Staff recruitment, induction and mentoring

COM2B: EIA team selection processes

COM2C: Internal EIA communication and feedback

COM2D: Performance management and EIA team development

Figure 6 The development of knowledge and learning in EIA Quality Mark registrants 
COM7 is designed to assist the learning process - although double-loop learning still relies on organisations reflecting against the best practice they are exposed to. Hence it assesses the extent to which the means of facilitating double-loop learning are available, rather than the existence of double-loop learning.

\subsection{Comprehensive involvement}

For the EIA Quality Mark, the interviews evaluate the provision of effective communications on EIA to clients and the extent to which consistent direction is provided on the approach to communicating with EIA stakeholders (see Figure 7). It is well known that a number of barriers exist to public participation in EIA (Diduck and Sinclair, 2002), and the EIA Quality Mark addresses this by endeavouring to evaluate not just the legal compliance of participation requirements, but also that expectations for good practice are followed. The EIS review expects to see a description of the consultation which took place and whether it included statutory and non-statutory consultees, and the public; and a summary of the issues raised through engagement and how they have been dealt with (including justification for any issue not dealt with)(Figure 8).

No sanctions are possible on the specific EIA if these are not satisfied based on the EIA Quality Mark. For non-market control mechanisms, the expectation is that non-compliance with legal requirements for comprehensive involvement would lead to additional work being requested, or license refusal.

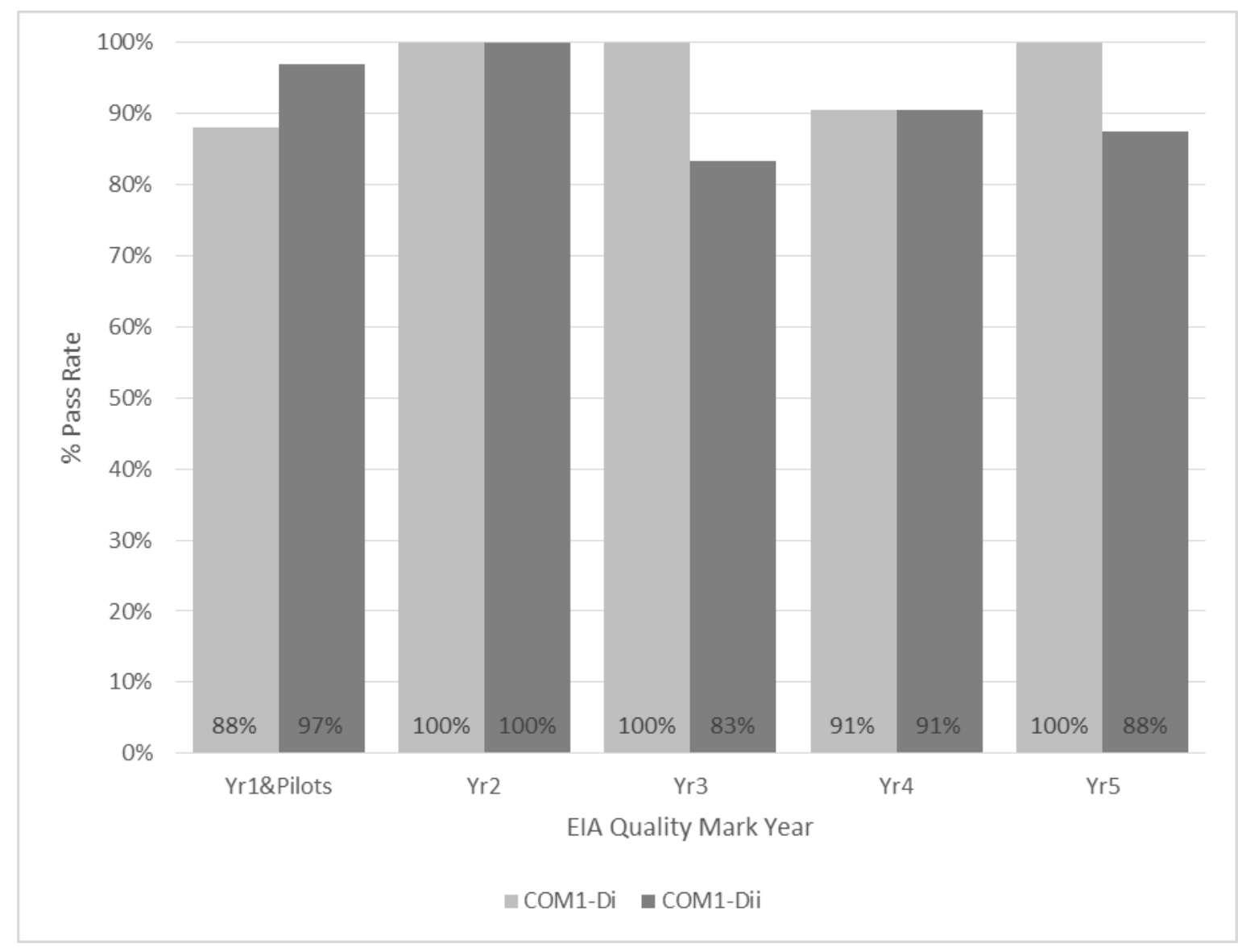

COM1-Di: Providing effective communications on EIA to clients 
COM1-Dii: Providing consistent direction on the approach to communicating with EIA stakeholders

Figure 7 The quality of external EIA communication by EIA Quality Mark registrants

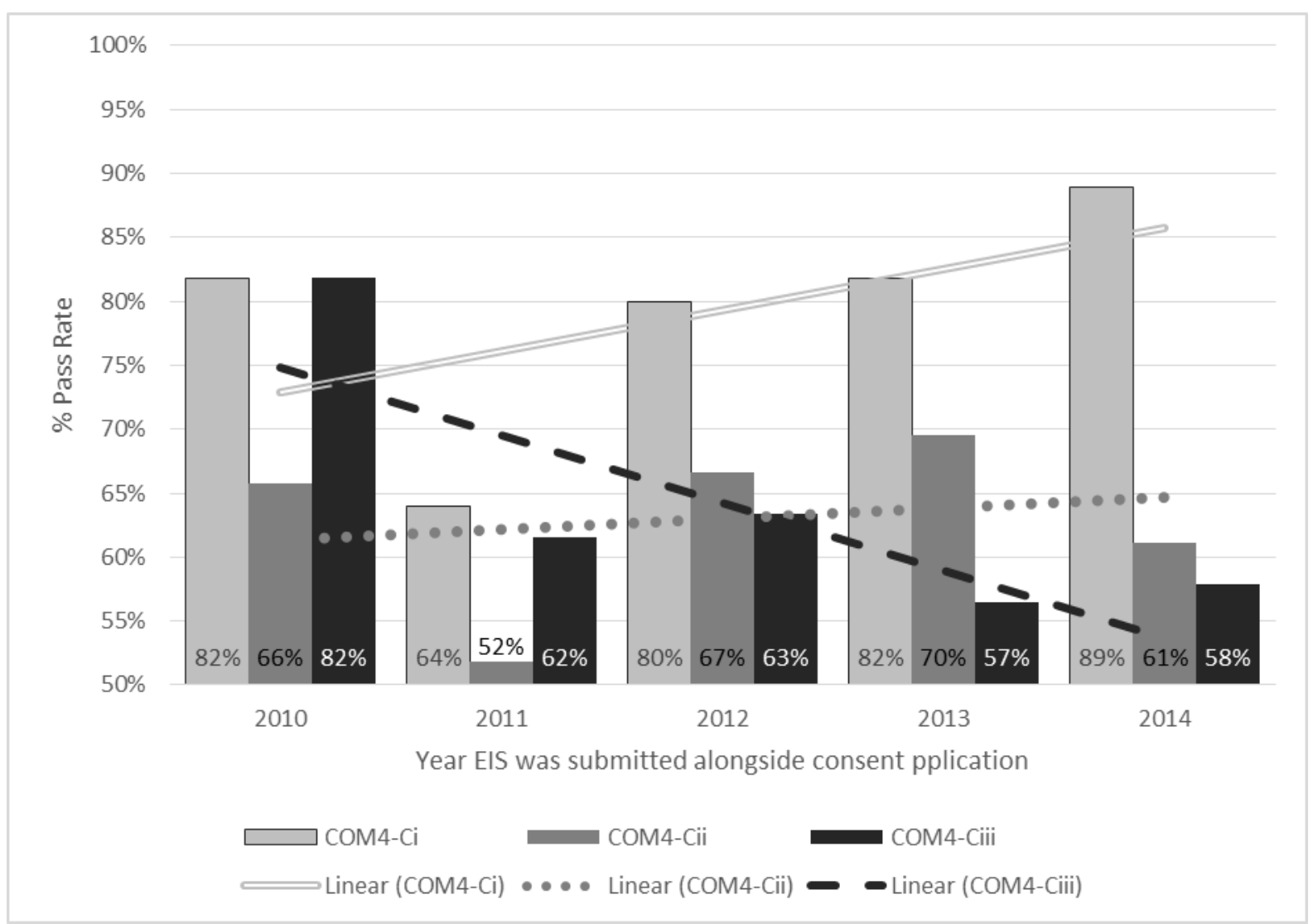

COM4-Ci: Does the description of any consultation include an indication of those contacted, including statutory and non-statutory consultees, and the public?

COM4-Cii: Does the main text of the ES provide a summary of the main issues, pertinent to the EIA, raised by consultees?

COM4-Ciii: Does the ES set out if any of the issues pertinent to the EIA raised by consultees will not be dealt with in the ES? If so is clear justification set out as to why the issue was scoped out?

Figure 8 The quality of EIA consultation by EIA Quality Mark registrants

\section{Conclusions}

Table 5 sets out the authors' evaluation of the EIA Quality Mark scheme, working along with existing procedural and judiciary control mechanisms in terms of delivering an effective EIA process, based on the dimension of effectiveness set out in this paper. 
Table 5 Evaluation of the EIA Quality Mark Scheme

\begin{tabular}{|c|c|c|}
\hline & $\begin{array}{l}\text { Provided by existing legal } \\
\text { procedure and Court } \\
\text { enforcement }\end{array}$ & $\begin{array}{l}\text { Provided by the EIA Quality } \\
\text { Mark }\end{array}$ \\
\hline Procedural compliance & $\begin{array}{l}\checkmark \text { - legal provisions and } \\
\text { enforcement by the courts }\end{array}$ & $\begin{array}{l}\checkmark-\text { the review evaluates } \\
\text { compliance based on the } \\
\text { legislation }\end{array}$ \\
\hline $\begin{array}{l}\text { Completeness of EIA } \\
\text { documents }\end{array}$ & $\begin{array}{l}\text { ? - the requirement for } \\
\text { comprehensive scoping is still } \\
\text { discretionary, although the } \\
\text { documents include } \\
\text { assessments of all items } \\
\text { scoped as potentially } \\
\text { significant }\end{array}$ & $\begin{array}{l}\checkmark-\text { the review is based on } \\
\text { best practice scoping } \\
\text { approaches which exceed } \\
\text { legal minimum requirements, } \\
\text { and the inclusion of } \\
\text { assessments of all items } \\
\text { scoped as potentially } \\
\text { significant in the document }\end{array}$ \\
\hline Methods to assess impacts & $\begin{array}{l}\mathrm{X} \text { - methods are left to the } \\
\text { authors to explain and justify }\end{array}$ & $\begin{array}{l}\text { ? - there is an expectation } \\
\text { that methods are clearly } \\
\text { stated and are consistent and } \\
\text { justified, but reviews are not } \\
\text { undertaken by experts who } \\
\text { can evaluate the specific } \\
\text { appropriateness of methods } \\
\text { used }\end{array}$ \\
\hline Influence on project decisions & $\begin{array}{l}\text { ? - legislation dictates that the } \\
\text { EIS must be considered prior } \\
\text { to making a decision, but this } \\
\text { does not necessarily exert } \\
\text { influence }\end{array}$ & $\begin{array}{l}\text { ? - influence is examined - } \\
\text { though this remains a weak } \\
\text { area of practice }\end{array}$ \\
\hline $\begin{array}{l}\text { Development of knowledge } \\
\text { and learning }\end{array}$ & $\begin{array}{l}\mathrm{X} \text { - there is no current } \\
\text { requirement to develop } \\
\text { knowledge and learning }\end{array}$ & $\begin{array}{l}\checkmark \text { - there is significant cross } \\
\text { checking of knowledge and } \\
\text { learning, with COM1 } \\
\text { investigating systems, and } \\
\text { COM2 determining whether } \\
\text { the internal company systems } \\
\text { are delivering as expected. } \\
\text { COM7 incorporates measures } \\
\text { to share knowledge with a } \\
\text { wider practitioner community }\end{array}$ \\
\hline
\end{tabular}




\begin{tabular}{|l|l|l|}
\hline Comprehensive involvement & $\begin{array}{l}\text { ?-there are legal minimums } \\
\text { in terms of public consultation, } \\
\text { but these occur at the decision } \\
\text { stage and fall short of } \\
\text { engagement that necessarily } \\
\text { influences the EIA }\end{array}$ & $\begin{array}{l}\checkmark \text { - expectations for } \\
\text { consultation cover } \\
\text { appropriate training of staff, } \\
\text { and appropriate coverage of } \\
\text { different stakeholder sets at } \\
\text { different stages of the EIA - } \\
\text { based on expectations for best } \\
\text { practice rather than legal } \\
\text { compliance }\end{array}$ \\
& & \\
\hline
\end{tabular}

$\checkmark$ = is covered; ? = incompletely covered; $\mathrm{X}=$ not covered.

Based on the analysis presented, it is clear that EIA Quality Mark registrants generally deliver a high level of effectiveness as measured by the dimensions of effectiveness used in this research, though we acknowledge that other interpretations of effectiveness exist and these would inevitably influence this conclusion.

The EIA Quality Mark applies only to registrants, whereas the existing legal and judicial framework applies to all consultants. Nevertheless, on a country-basis, the EIA Quality Mark can only be definitively linked to a third of UK EIAs undertaken each year, despite the majority (>92\%) of the UK's largest 25 EIA consultancies being counted amongst its 56 registered organisations. The inference is that the others will still deliver procedural compliance and a level of completeness of EIA documents, but the situation with respect to the other dimensions of effectiveness is unknown. In the context of the changing requirements of the EU EIA Directive, to ensure EISs are prepared by 'competent experts', the evaluation summarised in Table 5 suggests that the EIA Quality Mark might provide an appropriate market-based mechanism for meeting forthcoming legal obligations. Indeed, the scheme has seen a consistent growth rate in approved registrants of over $8 \%$ per year since 2012, when the European Commission first published proposals to include a 'competent experts' provision in the revision of the Directive. This suggests that organisations employing practitioners are viewing the EIA Quality Mark as a likely means for ensuring competence in the United Kingdom in the expectation that Government will not introduce any other schemes which would require the use of public money.

The time series evidence suggests modest improvements in practice over time, though there are clearly variations, and in some areas practice seems to have weakened slightly. Nevertheless, the monitoring enabled by the scheme allows identification of areas of strength and weakness, and allows IEMA to focus on improving practice where necessary through the obligations imposed on registrants to share knowledge with others. Whilst causality will be difficult to demonstrate in terms of improved practice stemming specifically from operation of the EIA Quality Mark, it does provide the evidence and opportunity needed, and sets expectations for a level of quality necessary for continued registration.

The international investigation of professional and evaluative control measures clarifies that the EIA Quality Mark has no influence on individual EIAs. Instead, it acts to verify the competence of practitioners, plus that of the support systems within the organisations that employ them, and helps to highlight areas of practice where improvements are required, and develops a community of 
practice to push forward improvements. It very much operates to improve the EIA system rather than individual EIAs.

We would argue, therefore, that the EIA Quality Mark is helping to deliver effective EIA in the UK, albeit limited to organisations willing to voluntarily commit to and fund its on-going registration requirements. And that it presents a useful model of a market-based mechanism for delivering effective EIA, as measured by the typology used in this research. However, these conclusions should be carefully caveated: The EIA Quality Mark has demonstrated, in the context of a mature EIA system in a developed country that it can provide an efficient market-based mechanism for delivering forms of control not already guaranteed by the legal procedures in place backed up by an active judiciary. We have no evidence to suggest it would provide a suitable solution outside this context.

\section{References}

Arts, J, H A C Runhaar, T B Fischer, U Jha-Thakur, F Van Laerhoven, P P J Driessen and V Onyango (2012), "The effectiveness of EIA as an instrument for environmental governance: Reflecting on 25 years of EIA practice in the netherlands and the uk", Journal of Environmental Assessment Policy and Management, 14(4), pages 1250025.

Badr, E-S A, M Cashmore and D Cobb (2004), "The consideration of impacts upon the aquatic environment in Environmental Impact Statements in England and Wales", Journal of Environmental Assessment Policy and Management, 6(1), pages 19-49.

Baker, D C and J N McLelland (2003), "Evaluating the effectiveness of British Columbia's environmental assessment process for first nations' participation in mining development", Environmental Impact Assessment Review, 23(5), pages 581-603.

Barker, A and C Wood (1999), "An evaluation of EIA system performances in eight EU countries", Environmental Impact Assessment Review, 19(4), pages 387404.

Bond, A, A Morrison-Saunders and R Howitt (2013), "Chapter 8: Framework for comparing and evaluating sustainability assessment practice", in A Bond, A Morrison-Saunders and R Howitt (editors), Sustainability Assessment: Pluralism, Practice and Progress (Taylor and Francis, London) pages 117131.

Bond, A J, L Langstaff, R Baxter, H-G Wallentinus, J Kofoed, K Lisitzin and S Lundström (2004), "Dealing with the cultural heritage aspect of environmental impact assessment in Europe", Impact Assessment and Project Appraisal, 22(1), pages 37-45.

Bond, A J and G Stewart (2002), "Environment Agency scoping guidance on the environmental impact assessment of projects", Impact Assessment and Project Appraisal, 20(2), pages 135-142.

Byron, H J, J R Treweek, W R Sheate and S Thompson (2000), "Road Developments in the UK: An Analysis of Ecological Assessment in Environmental Impact Statements Produced between 1993 and 1997", Journal of Environmental Planning and Management, 43(1), pages 71-97. Canter, L W (1996), Environmental Impact Assessment (McGraw-Hill, New York). 
Cashmore, M and A Axelsson (2013), "The mediation of environmental assessment's influence: What role for power?", Environmental Impact Assessment Review, 39, pages 5-12.

Cashmore, M, A Bond and D Cobb (2008), "The role and functioning of environmental assessment: Theoretical reflections upon an empirical investigation of causation", Journal of Environmental Management, 88(4), pages 1233-1248.

Cashmore, M, A Bond and B Sadler (2009), "Introduction: The effectiveness of impact assessment instruments", Impact Assessment and Project Appraisal, 27(2), pages 91-93.

Cashmore, M, R Gwilliam, R Morgan, D Cobb and A Bond (2004), "The interminable issue of effectiveness: substantive purposes, outcomes and research challenges in the advancement of environmental impact assessment theory", Impact Assessment and Project Appraisal, 22(4), pages 295-310.

Chang, T, E Nielsen, W Auberle and F I Solop (2013), "A quantitative method to analyze the quality of EIA information in wind energy development and avian/bat assessments", Environmental Impact Assessment Review, 38, pages $142-150$.

Charlier, R H (1996), "Environmental impact legislation assessments and audits: national legislation and EIA implementation in Belgium", International journal of environmental studies, 51(1), pages 1-19.

Commission of the European Communities (1997), Update of 5-years EIA report, review of the implementation of Directive 85/337/EEC, covering the timeperiod from 1990 to the end of 1996, and undertaken on the Commission's own initiative. (Commission of the European Communities, Directorate General XI, Brussels).

Council of the European Communities (1985), "Council Directive of 27 June 1985 on the assessment of the effects of certain public and private projects on the environment (85/337/EEC)", Official Journal of the European Communities, C175, pages 40 - 49.

Council of the European Union (1997), "Council Directive 97/11/EC of 3 March 1997 amending Directive 85/337/EEC on the assessment of the effects of certain public and private projects on the environment", Official Journal of the European Communities, 40(L73), pages 5-14.

De Jong, A A, H A C Runhaar, P R Runhaar, A J Kolhoff and P P J Driessen (2012), "Promoting system-level learning from project-level lessons. An analysis of donor-driven 'indirect' learning about EIA systems in Ghana and the Maldives", Environmental Impact Assessment Review, 33(1), pages 23-31.

Diduck, A and A J Sinclair (2002), "Public involvement in environmental assessment: The case of the nonparticipant", Environmental Management, 29(4), pages 578-588.

Ehrlich, A and W Ross (2015), "The significance spectrum and EIA significance determinations", Impact Assessment and Project Appraisal, 33(2), pages 8797.

EIA Centre University of Manchester, Land Use Consultants and Department for Communities and Local Government (2006), Evidence Review of Scoping in Environmental Impact Assessment (DCLG, London) 70.

Environment Analyst (2015), "UK environmental consulting sector growth accelerates", available at <https://environment-analyst.com/7363/uk- 
environmental-consulting-sector-growth-accelerates>, last accessed 14 October 2015.

Environmental Resources Management (2001a), Guidance on EIA - EIS Review

(Commission of the European Communities, Brussels) $32 \mathrm{pp}$.

Environmental Resources Management (2001b), Guidance on ElA - Scoping

(Commission of the European Communities, Brussels) $38 \mathrm{pp}$.

European Parliament and the Council of the European Union (2011), "Directive

2011/92/EU of the European Parliament and of the Council of 13 December

2011 on the assessment of the effects of certain public and private projects on

the environment (codification)", Official Journal of the European Communities,

55(L26), pages 26/1-26/21.

European Parliament and the Council of the European Union (2014), "Directive 2014/52/EU of the European Parliament and of the Council of 16 April 2014 amending Directive 2011/92/EU on the assessment of the effects of certain public and private projects on the environment", Official Journal of the European Communities, L124, pages 1-18.

Fischer, T B (2010), "Reviewing the quality of strategic environmental assessment reports for English spatial plan core strategies", Environmental Impact Assessment Review, 30(1), pages 62-69.

Fischer, T B and J Fothergill (2014), "Das IEMA UVP Gütezeichen im Vereinigten Königreich: Ein Beispiel freiwilliger Akkreditierung", UVP Report, 28(3+4), pages 113-118.

Fischer, T B, S Kidd, U Jha-Thakur, P Gazzola and D Peel (2009), "Learning through EC directive based SEA in spatial planning? Evidence from the Brunswick Region in Germany", Environmental Impact Assessment Review, 29(6), pages 421-428.

Fredsgaard, M W, B Cave and A Bond (2009), "A review package for Health Impact Assessment reports of development projects", available at $<$ http://bit.ly/k63NtC>, last accessed 29th November 2016.

Glasson, J and N N B Salvador (2000), "EIA in Brazil: A procedures-practice gap. A comparative study with reference to the European Union, and especially the UK", Environmental Impact Assessment Review, 20(2), pages 191-225.

Glasson, J, R Therivel and A Chadwick (2012), Introduction to Environmental Impact Assessment (Routledge, London).

Glasson, J, R Therivel, J Weston, E Wilson and R Frost (1996), "Changes in the Quality of Environmental Statements for Planning Projects", Environmental Assessment, 4(3), pages 96-97.

Hanna, P, F Vanclay, E J Langdon and J Arts (2014), "Improving the effectiveness of impact assessment pertaining to Indigenous peoples in the Brazilian environmental licensing procedure", Environmental Impact Assessment Review, 46, pages 58-67.

Hayes, N and A Morrison-Saunders (2007), "Effectiveness of environmental offsets in environmental impact assessment: practitioner perspectives from Western Australia", Impact Assessment and Project Appraisal, 25(3), pages 209-218.

IEMA (2011), "Special Report - the state of environmental impact assessment in the UK", available at <https://www.iema.net/system/files/iema20special20report20web.pdf>, last accessed 17 January 2013. 
Jha-Thakur, U, P Gazzola, D Peel, T B Fischer and S Kidd (2009), "Effectiveness of strategic environmental assessment - the significance of learning", Impact Assessment and Project Appraisal, 27(2), pages 133-144.

Lawrence, D P (1997), "Quality and effectiveness of environmental impact assessments: lessons and insights from ten assessments in Canada", Project appraisal, 12(4), pages 219-232.

Lawrence, D P (2007), "Impact significance determination - designing an approach", Environmental Impact Assessment Review, 27(8), pages 730-754.

Lee, N and D Brown (1992), "Quality control in environmental assessment", Project Appraisal, 7(1), pages 41-45.

Lee, N and R Colley (1992), "Reviewing the Quality of Environmental Statements. Second edition.", Occasional Paper Number 24.

Lee, N, R Colley, J Bonde and J Simpson (1999), Reviewing the Quality of Environmental Statements and Environmental Appraisals. Occasional Paper 55 (EIA Centre, University of Manchester, Manchester) 72.

Macrory, R (1994), "First European Court ruling on environmental assessment", ENDS Report, 237, pages 43.

Morgan, R K (2012), "Environmental impact assessment: the state of the art", Impact Assessment and Project Appraisal, 30(1), pages 5-14.

Morrison-Saunders, A and M Bailey (2009), "Appraising the role of relationships between regulators and consultants for effective EIA", Environmental Impact Assessment Review, 29(5), pages 284-294.

Ortolano, L (1993), "Controls on project proponents and environmental impact assessment effectiveness", Environmental Professional, 15(4), pages 352363.

Phylip-Jones, J and T B Fischer (2013), "EIA for wind farms in the United Kingdom and Germany", Journal of Environmental Assessment Policy and Management, 15(2).

Pinho, P, R Maia and A Monterroso (2007), "The quality of Portuguese Environmental Impact Studies: The case of small hydropower projects", Environmental Impact Assessment Review, 27(3), pages 189-205.

Runhaar, H, P R Runhaar and T Oegema (2010), "Food for thought: Conditions for discourse reflection in the light of environmental assessment", Environmental Impact Assessment Review, 30(6), pages 339-346.

Sadler, B (1996), International Study of the Effectiveness of Environmental Assessment Final Report - Environmental Assessment in a Changing World: Evaluating Practice to Improve Performance. (Minister of Supply and Services Canada, Ottawa) 248.

Sánchez, L (2013), "Development of environmental impact assessment in Brazil", UVP-report, 27(4+5), pages 193-200.

Sanchez, L E (1993), "Environmental Impact Assessment in France", Environmental Impact Assessment Review, 13, pages 255-265.

Sinclair, A J and A P Diduck (2001), "Public involvement in EA in Canada: a transformative learning perspective", Environmental Impact Assessment Review, 21(2), pages 113-136.

Smith, M D (2007), "A review of recent NEPA alternatives analysis case law", Environmental Impact Assessment Review, 27(2), pages 126-144.

Theophilou, V, A Bond and M Cashmore (2010), "Application of the SEA Directive to EU structural funds: perspectives on effectiveness", Environmental Impact Assessment Review, 30(2), pages 136-144. 
Thompson, S, J R Treweek and D J Thurling (1997), "The Ecological Component of Environmental Impact Assessment: A Critical Review of British Environmental Statements", Journal of Environmental Planning and Management, 40(2), pages 157-171.

Tromans, S and K Fuller (2003), Environmental Impact Assessment - Law and Practice (LexisNexis, London).

Wang, Y, R K Morgan and M Cashmore (2003), "Environmental impact assessment of projects in the People's Republic of China: new law, old problems", Environmental Impact Assessment Review, 23(5), pages 543-579.

Weston, J (2000), "EIA, Decision-making Theory and Screening and Scoping in UK Practice", Journal of Environmental Planning and Management, 43(2), pages 185-203.

Weston, J (2002), "From Poole to Fulham: A Changing Culture in UK Environmental Impact Assessment Decision Making?", Journal of Environmental Planning and Management, 45(3), pages 425-443.

Wood, C (2003), Environmental Impact Assessment: A Comparative Review (Prentice Hall, Edinburgh).

Wood, G (2000), "Ten years on: an empirical analysis of UK environmental statement submissions since the implementation of Directive 85/337/EEC", Journal of Environmental Planning and Management, 43(5), pages 721-747.

Wood, G, A Rodriguez-Bachiller and J Becker (2007), "Fuzzy sets and simulated environmental change: evaluating and communicating significance in environmental impact assessment", Environment and Planning A, 39, pages 810-829. 